\title{
DIVISÕES DIGITAIS EM PORTUGAL E NA EUROPA PORTUGAL AINDA À PROCURA DO COMBOIO EUROPEU?
}

\author{
DIGITAL DIVIDES IN PORTUGAL AND EUROPE \\ IS PORTUGAL STILL CHASING THE EUROPEAN TRAIN?
}

\author{
Tiago Lapa \\ Instituto Universitário de Lisboa (ISCTE-IUL) \& Centro de Investigação e Estudos de Sociologia (CIES-IUL). \\ Edifício Sedas Nunes, Av. das Forças Armadas, 1649-026 Lisboa, Portugal. Email: tjfls1@iscte-iul.pt \\ Jorge Vieira \\ Instituto Universitário de Lisboa (ISCTE-IUL) \& Centro de Investigação e Estudos de Sociologia (CIES-IUL). \\ Edifício Sedas Nunes, Av. das Forças Armadas, 1649-026 Lisboa, Portugal. Email: Jorge_Vieira@iscte-iul.pt
}

\begin{abstract}
Resumo: Este artigo avalia a situação portuguesa no quadro da sociedade informacional, adotando para o efeito uma perspetiva comparada entre grupos sociais e sociedades. Recorrendo aos dados do Eurostat, Portugal evidencia fragilidades persistentes face ao desenvolvimento informacional de outras sociedades europeias. Adota-se como pressuposto que as fraturas digitais entre grupos sociais e territórios assumem um papel chave na (re)produção de outras desigualdades sociais. Ou seja, constituem indicadores de desenvolvimento por excelência. Focalizando Portugal, foram usados dados da Entidade Reguladora para a Comunicação Social e do Inquérito Sociedade em Rede do CIES-IUL, de modo a imprimir uma análise complementar e diacrónica. Sustenta-se que, apesar da maior democratização do acesso às tecnologias da informação e comunicação, o conceito de fosso digital mantém-se relevante no contexto português, visto que os dados revelam associações apreciáveis entre acesso, usos e tipos de uso digitais, e as desigualdades sociais.
\end{abstract}

Palavras-chave: fosso digital, novos media, desigualdades, Portugal.

\begin{abstract}
This article evaluates the Portuguese situation in the framework of information society, adopting a comparative perspective between social groups and societies. Using Eurostat data, Portugal reveals prevailing fragilities in relation to the informational development of other European societies. It is assumed that digital divides between groups and territories play a key role in the (re)production of other social inequalities. In other words, they constitute indicators of societal development par excellence. Focusing in Portugal, data from the Portuguese Regulatory Authority for the Media (ERC) and from the CIES-IUL Network Society Survey were used to obtain a complementary and diachronic analysis. Despite the greater democratization of access to information and communication technologies, the concept of digital divide remains relevant in the Portuguese context. This is the case since the data reveal appreciable associations between digital access, uses and types of use, and social inequalities.
\end{abstract}

Keywords: digital divide, new media, inequalities, Portugal.

\section{Introdução}

Até 1995, as questões relativas ao desenvolvimento informacional de Portugal estavam apenas implícitas nas Políticas e Programas Governamentais, passando 
desde então a existir várias referências à Sociedade da Informação nos sucessivos programas de governos constitucionais. A iniciativa portuguesa para a criação de uma Sociedade da Informação foi baseada no Programa do $13^{\circ}$ Governo Constitucional, que delineou as intenções do Governo para o período 1995-1999. As Opções de Planeamento para 1996 lançaram a Iniciativa Nacional para a Sociedade da Informação, estruturada em torno de quatro eixos principais: a escola (Tecnologias da Informação na Educação); a empresa informatizada; a administração Pública local e regional; e a disponibilização de conhecimento (bibliotecas, museus, bancos de dados, instituições de investigação e desenvolvimento).

A resolução do Conselho de Ministros, $\mathrm{n}^{\circ}$. 16/96, aprovada em 21 de março de 1996, criou a Missão para a Sociedade da Informação (MSI), subordinada ao Ministério da Ciência e Tecnologia. Os principais objetivos da MSI foram preparar e suportar, em colaboração com todos os Ministérios, medidas globais e setoriais necessárias para realizar os programas governamentais para o desenvolvimento da Sociedade da Informação; e identificar cenários internacionais, nos níveis tecnológico e societal, que possam ter impacto no desenvolvimento da Sociedade da Informação. Neste quadro, Portugal tem vindo a desenvolver políticas e estratégias para a sua implementação no quadro da estratégia mais ampla da União Europeia. Um marco na estratégia política portuguesa para o desenvolvimento de uma Sociedade da Informação é o 'Livro verde para a sociedade da informação em Portugal', publicado em 1997 pelo Ministério da Ciência e Tecnologia, que constituiu um Plano Nacional contendo as medidas de curto, médio e longo prazos para a criação de uma Sociedade da Informação em Portugal.

São ainda de relevar políticas públicas posteriores, nomeadamente as que se sucederam pouco depois da passagem do milénio (2005-2011), período reconhecido publicamente como "choque tecnológico". Desse período, surgiram estudos pontuais e circunscritos, que se propuseram aferir o impacto destas políticas, nomeadamente nas crianças e na educação, como o de Pereira e Melro (2014). De notar que há muito por explorar quanto ao impacto destas políticas na vida dos adultos, desde a sua relação com o Estado e empresas, até aos hábitos de consumo e informativos. Apesar de terem constituído políticas de favorecimento do acesso e inclusão digital, Pereira e Melro defendem a ideia de que há nestas um pendor tecnocentrista na mitificação dos dispositivos tecnológicos, arrogados como geradores de transformação social e educacional. Como notam as autoras, não têm valorizado devidamente a capacitação individual e a comunidade e carecem de objetivos com vista à promoção da literacia mediática generalizada, que, para além do acesso e da compressão, agencie "a criação/produção, a interação, o pensamento crítico, a capacidade de seleção e de avaliação, a expressão e a participação dos cidadãos" (2014, p. 34). 
Ademais, é de salientar que o corte no "choque tecnológico" dos anos seguintes, devido a mudanças políticas e a constrangimentos económicos e financeiros no país, não foi acompanhado por processos de avaliação abrangentes e sistemáticos que permitissem a recolha de informação valiosa sobre os impactos das políticas tecnológicas levadas a cabo até então, tanto para investigadores como para decisores (Lapa, 2014). Se são de destacar programas em curso, muitos deles com apoio ou financiamento europeu, como o InCOde 2030 - que se apresenta como uma iniciativa de política pública dedicada especificamente ao reforço de competências digitais - não se sabe até que ponto os objetivos têm sido cumpridos, mesmo atendendo aos próprios constrangimentos estruturais da sociedade portuguesa.

Neste campo, há um trabalho minucioso por fazer que, por um lado, articule o acompanhamento das políticas públicas com indicadores de literacia digital e, por outro, analise de modo mais aprofundado o estágio de desenvolvimento informacional da sociedade portuguesa face a outros países europeus. É neste último propósito que o presente artigo se detém, ao analisar as divisões digitais em Portugal numa perspetiva comparada ao nível europeu, aferindo nesse contexto os recursos informacionais relativos da população portuguesa.

Este intento interliga-se com um par nuclear de objetivos. Por um lado, aferir o acesso e outras dimensões da literacia digital (Livingstone, 2004) da população em geral, numa perspetiva transeuropeia, uma análise que permite avaliar e situar Portugal enquanto sociedade informacional. Por outro, analisar fossos digitais no seio da sociedade portuguesa comparando para o efeito diferentes grupos sociais.

Coloca-se também a questão de saber até que ponto indicadores tradicionais de desigualdade e exclusão sociais explicam o fosso digital ente setores da sociedade portuguesa. Procede-se, deste modo, a uma interligação de fatores sociodemográficos com as formas de apropriação das tecnologias de informação e comunicação (TIC). Parte-se do princípio que as vidas digitais dos cidadãos têm muito pouco de "virtual" e assume-se a relevância dos fatores sociais offline nas modalidades de acesso e domesticação das redes digitais.

\section{Enquadramento teórico}

O conceito de fosso digital, que emergiu nos meados dos anos 90 no discurso académico e político (van Dijk, 2005), refere-se ao hiato entre os que têm acesso à informação e às TIC, entendidas como recursos que conferem vantagens, e indivíduos ou grupos sociais que não têm acesso. Tradicionalmente, os 'adotantes precoces' das TIC pertenciam a um grupo sociodemográfico restrito, em regiões desenvolvidas do planeta. Eram, nomeadamente, jovens ocidentais, do sexo masculino e 
brancos, atraídos e envolvidos nas novas tecnologias. Atualmente, é inegável a diversificação geográfica e sociodemográfica dos utilizadores das redes digitais.

Em contextos sociais de uso generalizado das TIC, o próprio conceito de fosso ou fratura digital tem evoluído para incluir desigualdades dentro de uma área geográfica, sociedade ou comunidade nas modalidades de uso e quanto ao conjunto de competências e saberes necessários para realizar tarefas de modo proficiente com as TIC (Vieira, 2015).

As análises sobre os potenciais impactos das TIC na sociedade dividem-se, em particular, no que respeita à relação entre as novas tecnologias e as desigualdades sociais existentes. Estas abordagens, no fundo, enfrentam questões sobre, por um lado, os nexos relacionais entre tecnologia, estrutura social e desigualdade e, por outro, o papel das desigualdades digitais enquanto promotoras de outras desigualdades em diferentes esferas do social. Quer do lado mais otimista, quer do lado de perspetivas mais pessimistas, assume-me que, de facto, a tecnologia tem efeitos e que há um carácter instrumental do acesso ao digital como propiciador ou inibidor de oportunidades no quotidiano e na própria mobilidade social.

Do lado mais otimista, Compaine (2001) defende a existência de efeitos equalizadores das tecnologias da informação e comunicação. O argumento central é que as TIC têm características intrínsecas que são potenciadoras de grandes mudanças em termos de difusão e descentralização da informação e do conhecimento enquanto recursos de poder, o que atenua as desigualdades sociais. No entanto, estas perspetivas têm sido acusadas de deterministas do ponto de vista tecnológico, uma vez que conferem à ação da tecnologia o principal fator (positivo) de mudança social e descontextualizam os efeitos dessa mesma ação.

Seguindo Castells (2000), os impactos das TIC não são unívocos e as suas manifestações dependem das estruturas sociais concretas, embora também sejam coproduzidas por agentes ativos, criativos e inovadores. Porém, daqui resulta uma questão teórica a ser desempatada por via empírica: qual é a natureza da relação entre estrutura social e TIC? Que efeitos tem uma parte sobre a outra? E qual tem maior ascendente sobre a outra? Como parte da resposta, outras análises recolocam as novas tecnologias, no essencial, como preservadoras da estrutura social vigente (Hargittai e Hsieh, 2013) e neutralizam assim, em larga medida, os potenciais efeitos sociais da tecnologia. Como corolário arroga-se que a inovação tecnológica acompanha e reproduz os processos de estratificação e de desigualdade previamente existentes.

No campo mais pessimista, temos abordagens que consideram as novas tecnologias como propiciadoras de processos de polarização social (Schiller, 1996), em que "os ricos ficam mais ricos". Em síntese, não há um caminho direto e mecanicista de estudar os efeitos sociais e individuais das redes digitais e, no seio das 
ciências sociais, não há uma uniformidade paradigmática de analisar o ciclo social dinâmico que compreende os fatores e características sociais offline, as práticas online e os seus efeitos sociais (Cardoso, Liang e Lapa, 2013). Se há quem chame a atenção para a necessidade de temperar o enfoque analítico no primado dos antecedentes offline, clamando pelos efeitos próprios da tecnologia e pela inclusão na pesquisa da inovação social derivada da agência dos atores online, há também aqueles que proclamam a primazia das propriedades estruturais dos sistemas sociais, concebidas como positivas ou negativas conforme as perspetivas, nas atividades digitais.

Se de um lado e de outro podemos, porventura, identificar exageros, o exame empírico no seio das sociedades ocidentais tem reiteradamente demonstrado persistentes desigualdades - digitais ou outras -, em particular, em sociedades desiguais como a portuguesa (Lapa, Vieira, Azevedo e Cardoso, 2018), o que constitui um revês à expectativa de que as TIC constituem uma força descentralizadora e niveladora das hierarquias e do poder. Tal constância advém igualmente da natureza dinâmica da evolução tecnológica que acompanha o processo de (re)produção social das desigualdades. Por exemplo, a gradual digitalização, ou a expansão do segmento de dispositivos portáteis e móveis (Blank e Dutton, 2012; Cardoso, Liang e Lapa, 2013), leva a novas camadas de desigualdade. Neste âmbito, o estatuto socioeconómico aparece como fator explicativo da posse de smartphones nos EUA (Smith, 2011), tal como no passado se destacava como um dos principais fatores na previsão do acesso à internet, à banda larga, entre outros recursos tecnológicos. Ademais, mesmo em cenários de acesso generalizado a uma dada tecnologia, as divisões digitais operam em várias dimensões ou ordens para além do acesso da e utilização.

Neste sentido, é de relevar a multidimensionalidade do conceito de fosso digital. Uma primeira ordem de desigualdades digitais concerne às desigualdades de acesso. Como argumentado, o acesso às TIC deve ser entendido como um processo dinâmico, em constante evolução, dado o avanço tecnológico e as mudanças de mercado que refletem modalidades cambiantes de consumo. A camada mais simples inclui o acesso, mas igualmente a utilização/não-utilização da tecnologia (mesmo que esteja garantido o acesso), o tipo e qualidade do acesso, entre outros fatores congéneres. Já o fosso concernente aos tipos de conhecimento e de literacia, às competências e proficiência digitais remetem para divisões de segunda ordem (Hargittai e Hsieh, 2013), relativas aos tipos de uso, aptidões e experiência dos internautas (DiMaggio, Hargittai, Celeste e Shafer, 2004). Neste quadro, van Dijk (2005) defende que as divisões de segunda ordem no âmbito das utilizações digitais podem ser mais severas que os fossos mediáticos respeitantes à utilização dos media tradicionais, uma vez que os novos media demandam novas aprendizagens, competências e habilidades. 
As análises que se debruçam sobre a domesticação dos novos media (Haddon, 2007) incluem ainda, frequentemente, tipologias de utilização (por exemplo, usos de entretenimento, instrumentais, educativos ou informativos, etc.), as atitudes e representações face à internet e modalidades de apropriação e incorporação tecnológica em contextos quotidianos domésticos, de lazer e trabalho. São análises que se prestam a combinações, por um lado, metodológicas, entre pesquisa quantitativa e qualitativa e, por outro, teóricas, articulando-se com perspetivas como a análise de coortes ou geracional e o trabalho de Bourdieu sobre capital social e cultural (Hynes e Rommes, 2005), por exemplo. Diferentes estudos em diversos contextos (Hargittai e Hinnart, 2008; Cardoso, Espanha e Araújo, 2009) têm demonstrado que aqueles com maiores competências digitais e mais recursos socioeconómicos, cognitivos, culturais, tendem a incorporar as tecnologias nas suas vidas de forma mais ampla e a utilizar as redes digitais mais frequentemente como ferramenta utilitária, de informação e como forma de estreitamento dos laços sociais. Por seu turno, os internautas mais desprivilegiados tendem a ser pautados por uma utilização cuja motivação é, principalmente, a procura de entretenimento.

Além disso, estão em cima da mesa propostas de aferição de divisões de terceira ordem (van Deursen e Helsper, 2015). Ou seja, em populações de utilizadores com padrões de uso genericamente semelhantes, propõem medir a capacidade de traduzir o uso das redes digitais em resultados tangíveis offline. Todavia, é possível alegar que a diferença entre estas divisões e as de segunda ordem não são totalmente claras. Neste sentido, Szeles (2018) argumenta que aquelas constituem um refinamento da noção de divisões de segunda ordem, visto que podemos considerar os resultados tangíveis como uma subdimensão da capacidade de apropriação crítica da informação ou da capacidade de produção de conteúdos digitais e de conhecimento mobilizáveis no quotidiano.

É de acrescentar que discussões conceptuais sobre os conceitos de infoexclusão e de não-utilização são fundamentais, pois informam a construção de instrumentos de pesquisa e a medição e interpretação de determinado fenómeno. Neste âmbito, aponta-se que nas sociedades informacionalmente desenvolvidas fará pouco sentido corresponder infoexclusão com não-utilização, ou assumir a não-utilização da internet automaticamente como uma situação de desvantagem (Reisdorf, 2011). Em sequência, podemos considerar infoexclusão apenas aquelas situações em que a não-utilização das redes digitais deriva de fatores tradicionais de exclusão, nas dimensões económica, social, cultural ou até mesmo territorial (Szeles, 2018). Estas perspetivas assinalam o peso dos processos decisionais e defendem que os conceitos de 'desigualdade' e 'fosso' devem dar lugar à noção de 'desafetação digital'. Por outro lado, chama-se à atenção para a importância do contexto social e das redes 
familiares, de amizade e de sociabilidade próxima em que os indivíduos, em particular, os não utilizadores, estão inseridos (Lapa, Vieira, Azevedo e Cardoso, 2018). Há que equacionar efeitos de grupo, dado que a inclusão digital generalizada pode potenciar formas intermédias de inclusão, apelidadas de 'inclusão por procuração', para aqueles que apresentam qualquer tipo de constrangimento no acesso e uso das redes digitais, mas que recorrem a terceiros para as usar em seu nome.

Do exposto, que pistas indiciam os dados sobre a situação portuguesa numa análise comparativa europeia? Qual o peso de indivíduos efetivamente infoexcluídos e de incluídos por procuração entre os não-utilizadores, em comparação com não-utilizadores de países europeus informacionalmente mais desenvolvidos?

\section{Notas metodológicas}

Considera-se que as comparações transnacionais de não-utilizadores da internet não são lineares visto que as leituras mais imediatistas dos dados poderão dar aso a interpretações erróneas. Ou seja, uma determinada percentagem de não-utilizadores da internet numa sociedade não quer dizer que esse dado seja um indicador de divisão ou desigualdade e que todos os não-utilizadores estejam em situação de exclusão. Essa caraterização só poderá ser feita mediante uma análise aprofundada que consiga aferir elos de associação entre fatores de exclusão (económica, social, cultural) e a não-utilização.

No âmbito de estudos e inquéritos nesta temática, é de destacar bases de dados disponíveis que serviram de suporte à análise dos dados desta pesquisa. Em primeiro lugar, socorremo-nos do Inquérito Sociedade em Rede (2003-2013) do CIES-IUL, que tem prestado o serviço de averiguar o desenvolvimento do acesso e utilização das TIC em Portugal desde o início do milénio. Foi igualmente utilizado o inquérito da Entidade Reguladora para a Comunicação Social (ERC) denominado "As novas dinâmicas do consumo audiovisual em Portugal" (ERC, 2016) ${ }^{1}$. No que respeita a dados do contexto europeu é de assinalar o acompanhamento feito pelo Eurostat, tendo sido aproveitadas as estatísticas de economia digital e sociedade para o ano de 2017, que permitem a análise comparada respeitante aos desenvolvimentos informacionais, de um ângulo sincrónico e diacrónico, evidenciando a permanência das fragilidades da sociedade portuguesa face ao desenvolvimento informacional de outros países. São ainda apresentados dados do Inquérito à Utilização de Tecnologias da Informação e da Comunicação pelas Famílias do INE (2017) como complemento aos retirados do Eurostat. A apresentação de dados destes inquéritos emprega como variáveis explicativas da utilização da internet fatores chave nos estudos em torno da desigualdade e exclusão, como a educação, o 
grau de urbanização, o rendimento do agregado doméstico, a condição perante o trabalho, entre outras variáveis.

\section{Resultados}

Os dados do Eurostat quanto ao acesso doméstico à internet mostram que, no contexto europeu, Portugal apresenta taxas de acesso tradicionalmente baixas nos agregados familiares ( $58 \%$ em 2011 e $77 \%$ em 2017), colocando o nosso país próximo do grupo de países com menores taxas de penetração doméstica da internet na EU-28. Como podemos observar na Tabela 1, países como o Luxemburgo, Holanda, Dinamarca e Suécia, apresentam taxas de utilização acima ou em torno dos $90 \%$, já em 2011, o que indicia divisões digitais entre grupos sociais menos pronunciadas. É no grupo de países com menores taxas de penetração nos agregados que são expectáveis diferenças e divisões digitais mais pronunciadas e interligações mais evidentes entre as divisões digitais (individuais, familiares e territoriais) e os processos de exclusão social (Lapa, Vieira, Azevedo e Cardoso, 2018). É, portanto, expectável que entre os não utilizadores portugueses se encontrem mais pessoas totalmente excluídas do ponto de vista informacional, i.e., sem suporte social quanto ao uso das TIC caso necessitem, face a países informacionalmente mais avançados.

Os dados do Inquérito Sociedade em Rede do CIES-IUL para 2011 confluem com os dados do Eurostat, uma vez que apresentam uma taxa de penetração da internet nos agregados familiares portugueses de cerca $57 \%$, valor que se manteve próximo em 2013. Porém, de acordo com o mesmo inquérito, a utilização efetiva da internet em 2011 era apenas 49,1\% em Portugal, tendo a discrepância entre o acesso em casa e a utilização diminuído quando comparando 2011 com 2013 (aferindo-se neste ano uma taxa de utilização de 55,2\%). Pelo menos no panorama português, o acesso doméstico tem sido maior que a utilização.

Um dos fatores explicativos dessa diferença é a presença de crianças no agregado familiar enquanto incitador de uma adoção célere do acesso às TIC em casa (Livingstone e Haddon, 2009; Lapa, 2014). De facto, os dados do INE para 2017 apontam que o acesso à internet em casa nas famílias com crianças é, atualmente, praticamente universal (97\%), em comparação com $70 \%$ entre os agregados sem crianças. Este valor decresce ainda mais entre os indivíduos que vivem sós (57\%). Se assumirmos que, no contexto português, muitos destes indivíduos são seniores e estão em situação de exclusão (Mauritti, 2011), não apenas na dimensão económica, mas em termos de integração social, este cenário de não acesso a uma tecnologia socializante como a internet, com implicações na organização da vida pessoal e 
familiar, vinca o panorama de exclusão para muitos dos que vivem sós. Demais, estamos a falar de um grupo onde tendencialmente a rede de apoio social se encontra mais rarefeita e que, pelas suas próprias circunstâncias, estará em menores condições para recorrer a formas intermédias de inclusão digital por procuração.

Ao compararmos 2011 com 2017, merece destaque a tendência de convergência na generalização do acesso no espaço doméstico, uma vez que a taxa média para o acesso à internet em casa é $87 \%$ para o total da UE-28. É ainda de destacar que, em 2017, verifica-se uma clara maioria de países europeus com uma taxa de acesso à internet em casa acima dos $80 \%$. Estes indicadores europeus salientam o panorama de atraso informacional de Portugal.

Ademais, o acesso à internet por dispositivos móveis serve como um indicador adicional de comparação transeuropeia de desigualdades quanto ao uso das redes digitais num contexto de convergência de acesso doméstico. No que respeita este indicador, Portugal, com 58\% de indivíduos dos 16 aos 74 anos que usam equipamentos móveis para aceder à internet fora de casa ou do trabalho, está abaixo da taxa total para a UE-28 (65\%) e longe de países nórdicos como a Holanda e a Suécia, que apresentam uma taxa de $87 \%$. Esta situação estará associada a menores recursos socioeconómicos e culturais da sociedade portuguesa face à parte desenvolvida da Europa.

Fazendo uma leitura dos indicadores relativos ao acesso por grau de urbanização, os dados do Eurostat espelham desigualdades territoriais assinaláveis entre países europeus e intra-societais em países como Portugal, Roménia, Grécia ou Bulgária. Nas sociedades informacionais mais desenvolvidas do Norte e Centro da Europa as diferenças territoriais por grau de urbanização são praticamente nulas ou mesmo inexistentes. Já em Portugal, a baixa taxa de acesso relativa acompanha a disparidade no acesso à internet entre as cidades, vilas e subúrbios e as áreas rurais. Neste panorama, identifica-se uma disparidade na taxa de acesso de cerca de 20 pontos percentuais (p.p.) entre as cidades portuguesas, em que a taxa de acesso é $83 \%$, e os territórios rurais, em que a taxa de acesso é $63 \%$.

Complementando com dados do INE, "é na Área Metropolitana de Lisboa que mais famílias têm ligação à internet em casa em 2017, apresentando proporções de acesso superiores em 9 p.p. à média nacional" (2017, p. 2). Também

nas regiões autónomas dos Açores e da Madeira se registam níveis de acesso em casa através de banda larga superiores à proporção nacional, respetivamente, com $84 \% \mathrm{e}$ $81 \%$. Pelo contrário, a região do Alentejo continua a apresentar os níveis de acesso à internet $(67 \%)$ e banda larga (66\%) mais baixos do país (INE, 2017, p. 2).

Estes dados demonstram importantes fraturas digitais territoriais passíveis de serem articulas com outros indicadores regionais de desenvolvimento e exclusão. Como 
Tabela 1 Indicadores de economia digital e sociedade (agregados familiares e indivíduos)

\begin{tabular}{|c|c|c|c|c|c|c|c|}
\hline & \multicolumn{2}{|c|}{$\begin{array}{c}\text { Acesso à internet dos } \\
\text { agregados familiares } \\
\text { (\% de todos os agregados })\end{array}$} & \multicolumn{2}{|c|}{$\begin{array}{c}\text { Indivíduos que usam } \\
\text { computadores portáteis } \\
\text { ou dispositivos móveis } \\
\text { para aceder à internet fora } \\
\text { de casa ou do trabalho } \\
\text { (\% de indivíduos dos } 16 \text { aos } \\
74 \text { anos) }\end{array}$} & \multicolumn{3}{|c|}{$\begin{array}{l}\text { Acesso à internet por grau } \\
\text { de urbanização, } 2017 \\
\text { (\% de todos os agregados) }\end{array}$} \\
\hline & 2011 & 2017 & 2012 & 2017 & Cidades & $\begin{array}{c}\text { Vilas } \\
\text { e subúrbios }\end{array}$ & Áreas rurais \\
\hline UE-28 & 73 & 87 & 36 & 65 & 90 & 87 & 82 \\
\hline Holanda & 94 & 98 & 55 & 87 & 98 & 98 & 97 \\
\hline Luxemburgo & 91 & 97 & 63 & 82 & 95 & 97 & 98 \\
\hline Dinamarca & 90 & 97 & 61 & 83 & 98 & 97 & 96 \\
\hline Suécia & 91 & 95 & $70\left({ }^{1}\right)$ & 87 & 97 & 95 & 92 \\
\hline Portugal & 58 & 77 & 21 & 58 & 83 & 77 & 63 \\
\hline Roménia & 47 & 76 & $7\left({ }^{1}\right)$ & 53 & 87 & 77 & 65 \\
\hline Lituânia & 60 & 75 & 17 & 55 & 83 & 78 & 67 \\
\hline Grécia & 50 & 71 & 23 & 53 & 80 & 73 & 57 \\
\hline Bulgária & 45 & 67 & 13 & 56 & 77 & 66 & 52 \\
\hline
\end{tabular}

(1) 2013 em vez de 2012.

Fonte: Eurostat

(http://ec.europa.eu/eurostat/statistics-explained/index.php/Digital_economy_and_society_statistics_-_household s_and_individuals\#Internet_usage

argumentam Skryabin, Zhang, Liu e Zhang (2015), grande parte da variação regional se deve a diferenças na composição socioeconómica. No entanto, ao comparar as regiões autónomas insulares com o Alentejo, tendo como critério indicadores socioeconómicos e o percurso de desenvolvimento que caraterizam essas regiões, não seriam de esperar disparidades tão vincadas.

Estas variações podem ser eventualmente atribuídas a fatores não económicos e mais especificamente locais, como o impacto regional de várias políticas. Será que políticas de promoção do acesso à internet nas regiões autónomas têm sido mobilizadas para colmatar desvantagens derivadas da sua condição insular? Desta forma, para perceber melhor as disparidades regionais é necessário atender, em pesquisas futuras, não apenas a políticas públicas de abrangência nacional, mas à sua implementação local e ao desenho de políticas tecnológicas com incidência regional.

Voltando ao panorama Europeu, curiosamente, a Roménia apresenta uma maior penetração do acesso à internet nas zonas citadinas (87\%) e ligeiramente maior nas zonas rurais (65\%) do que Portugal, embora apresente uma taxa de acesso global (76\%) ligeiramente menor que a República Portuguesa. Tais valores deverão espelhar uma maior população rural na Roménia e maior concentração populacional nas 
cidades em Portugal. Em geral, para o grupo dos países europeus informacionalmente menos desenvolvidos, pela via do acesso às TIC identificamos índices de desenvolvimento bastante distintos entre espaços urbanos e zonas rurais que espelham países digital e territorialmente fraturados.

Num tom mais positivo, olhando diacronicamente, a taxa de utilizadores em Portugal duplicou de 2003 (29\% de utilizadores, segundo dados do Inquérito Sociedade em Rede) para 2015 (60,5\% de utilizadores portugueses, segundo dados da ERC). Ademais, esse aumento foi acompanhado por uma diversificação sociodemográfica de utilizadores, não se registando atualmente diferenças de género de monta (como se pode constatar pela fraca associação entre uso da internet e género apresentada na Tabela 2, em baixo). Todavia, para Helsper (2010), nestas questões, os estudos existentes não fornecem uma visão completa de como o género interage com outros fatores sociodemográficos relacionados com o ciclo de vida, como a condição perante o trabalho ou o estado civil. Portanto, é difícil saber se, de facto, as diferenças de acesso e uso entre homens e mulheres desapareceram em larga medida. Acrescente-se que a presente análise não contempla os reflexos da ordem de género nas modalidades de uso e as suas implicações nas oportunidades de vida, para além do mero foco no acesso e utilização da internet.

Já outros fatores tradicionais de desigualdade como a escolaridade continuam a ter um evidente peso não só nas oportunidades de vida, em geral, mas igualmente nas taxas de uso da internet, como se pode ver na Figura 1, em baixo.

O diferencial de capital cultural institucionalizado (escolaridade), mais que as disparidades relativas ao capital económico (rendimento), surge como a principal variável explicativa do fosso digital de primeira ordem em Portugal. Fica evidente a exclusão digital generalizada dos indivíduos pouco escolarizados, muito deles seniores. Especificamente dentro dos recursos educacionais, os conhecimentos de inglês dos indivíduos estão bastante relacionados com a utilização da internet, como se vê na análise apresentada em baixo, realizada com os dados Sociedade em Rede para 2013. Além disso, comparando a utilização da internet entre escalões etários (ERC, 2016), o contexto português é caracterizado por hiatos geracionais de monta quanto ao uso da internet, em favor dos indivíduos mais novos. Como se pode testemunhar na Figura 2, onde constam dados de 2015, entre os indivíduos dos 12 aos 24 anos a utilização da internet é praticamente universal (97,8\%), enquanto os indivíduos portugueses com 65 ou mais anos constituem o único grupo etário onde se verifica uma taxa de uso abaixo dos $50 \%$.

Porém, é de notar que os significados e usos da tecnologia variam de acordo com uma série de variáveis para além do fator etário, sendo de evitar generalizações abusivas quanto às vidas digitais dos mais novos e dos seniores que poderão 


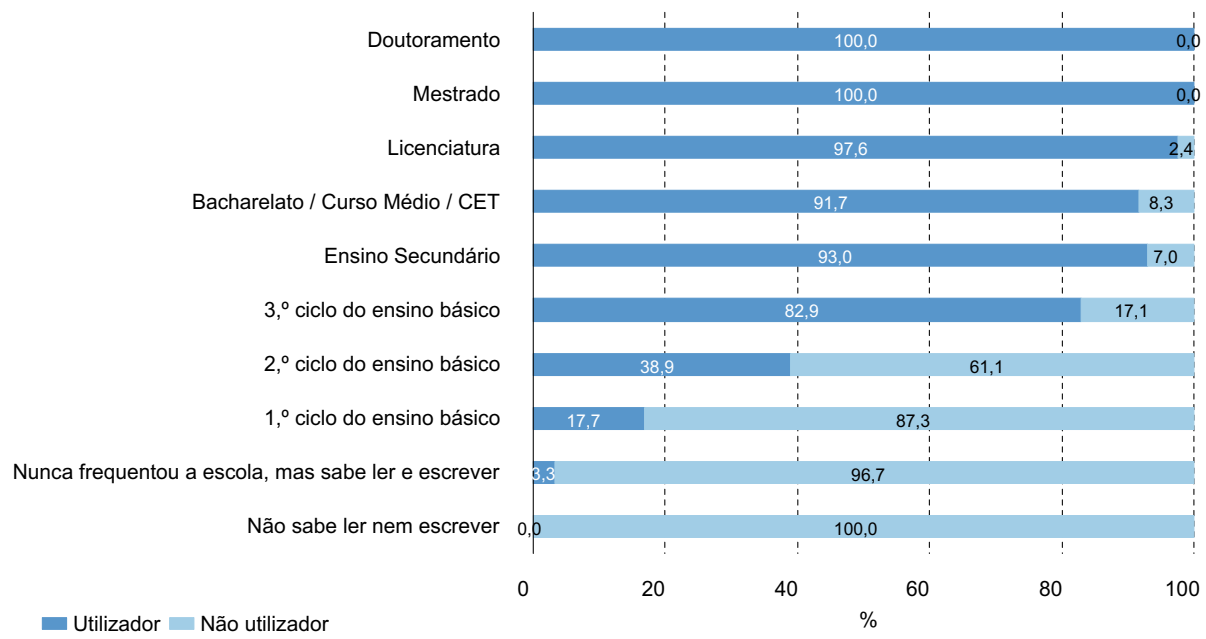

Figura 1 Capital cultural institucionalizado e acesso à internet

Fonte: ERC 2016, As novas dinâmicas do consumo audiovisual em Portugal ( $n=1018)$

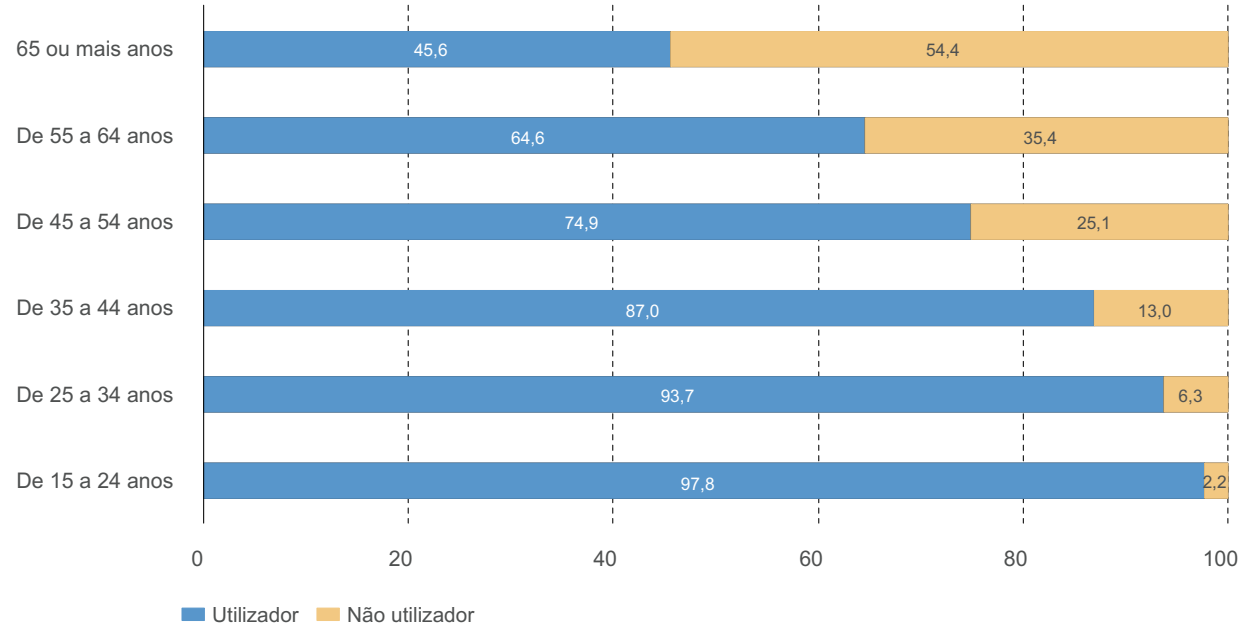

Figura 2 Divisões geracionais em Portugal? Taxa de utilização da internet, por idade Fonte: ERC 2016, As novas dinâmicas do consumo audiovisual em Portugal $(n=1018)$

encobrir condições assimétricas no seio da mesma coorte etária, concernentes a distribuições desiguais de recursos e literacias, e a presença de circunstâncias que poderão conferir (des)vantagens sociais, económicas, geográficas, de género, educacionais ou culturais (Lapa, 2014). 
Tabela 2 Fatores relevantes preditivos da utilização da internet (Variável dependente: Utilizador / não-utilizador)

\begin{tabular}{lc}
\hline Varável independente/explicativa & Coeficientes de associação/correlação \\
\hline Escolaridade (escalões) & 0,707 \\
Conhecimentos de inglês & 0,652 \\
Idade (contínua) & 0,613 \\
Condição perante o trabalho & 0,543 \\
Categoria socioprofissional do Pai & 0,431 \\
Estado civil & 0,427 \\
Rendimentos mensal líquido do agregado doméstico & 0,406 \\
Categoria socioprofissional da Mãe & 0,406 \\
Grupo profissional & 0,405 \\
Indicador socioprofissional ACM & 0,333 \\
Género & 0,083 \\
\hline
\end{tabular}

Fonte: Inquérito Sociedade em Rede, $2013(\mathrm{n}=1542)$

Como se pode verificar na Tabela 2, a variável escolaridade é a que apresenta o maior poder preditivo da utilização da internet com um coeficiente de associação forte de cerca de 0,7. A seguir, temos uma variável explicativa relacionada, os conhecimentos de inglês, que apresenta um coeficiente de associação de cerca de 0,65 com o uso da internet. A outra variável explicativa que fecha o top 3 é a idade, com um coeficiente de associação moderado, apresentando um valor acima do 0,6. São ainda exibidas outras variáveis relevantes na explicação da utilização da internet e que são igualmente utilizadas como fatores preditivos das situações de exclusão social.

Na Tabela 2, a condição perante o trabalho apresenta um coeficiente de associação com o uso da internet de 0,54 . Este indicador tem sido recorrentemente identificado como preditor não só da utilização da internet como de modalidades de uso mais ativas e frequentes. Tem sido também associado ao potencial de aumentar a participação na tomada de decisões e no uso de recursos no trabalho (Emmanouilides e Hammond, 2000) e na atuação no mercado de trabalho. Tal resultado é expectável devido ao impacto das redes digitais nas formas de organização dos processos de trabalho, gradualmente transformados para se ajustarem aos sistemas baseados na internet. Assim, como apontam os dados do INE de 2017, é mais provável que um indivíduo empregado use a internet (em $86 \%$ dos casos) que um indivíduo desempregado (71\%). Os extremos são representados pelos estudantes, com uma taxa de utilização de $100 \%$, e pela categoria de 'outros inativos', com uma taxa de utilização de $38 \%$.

Estes dados são, na generalidade, confluentes com os dados da ERC para 2015 que revelam identicamente que, para além da escolaridade e da idade, a condição perante o trabalho, constitui outro fator marcante que enforma o uso 
estruturalmente desigual da internet. Neste inquérito, as taxas de utilização mais significativas surgem nas condições de estudante e de trabalhador a tempo inteiro ( $98,6 \%$ e $82,6 \%$, respetivamente). As menores taxas de uso aparecem entre desempregados/as com subsídio (45,3\%), domésticos/as (30\%), reformados/as (18,4\%) e aqueles que estão incapacitados permanentemente para o trabalho. Isto representa o reflexo das camadas de exclusão que as pessoas incapacitadas e/ ou em condições vulneráveis acumulam e dos desafios que essas pessoas enfrentam no quotidiano, onde se incluem os desafios tecnológicos para uma inclusão plena nos vários planos da Sociedade da informação.

A categoria socioprofissional do pai, o estado civil, o rendimento mensal líquido do agregado doméstico, a categoria socioprofissional da mãe e o grupo profissional do próprio são fatores explicativos que apresentam coeficientes de associação apreciáveis, rondando os 0,4 . No que concerne ao peso do estado civil, os dados indicam uma associação positiva entre conjugalidade e utilização da internet. Como referimos, agregados familiares mais alargados aparecem associados a taxas de utilização maiores, mesmo em agregados sem crianças. Segundo dados do INE (2017), a taxa de utilização da internet dos agregados com dois adultos é maior (65\%) do que a taxa de utilização dos agregados com um adulto (57\%). Para este cenário contribuirá certamente o peso dos seniores a viver sós e/ou em situação de viuvez.

Nota-se também a relevância da 'herança' familiar por via do peso das categorias socioprofissionais dos ascendentes, havendo pouco distanciamento entre $o$ peso da categoria socioprofissional do pai em comparação com a da mãe. Num contexto de acesso generalizado à internet nas camadas populacionais mais jovens, é de salientar que estes fatores ainda aparecem como relevantes na análise devido ao peso das situações desprivilegiadas dos ascendentes mais seniores. É de esperar um esbatimento futuro do peso destes fatores, quanto ao acesso às redes digitais.

Em geral, os dados mostram que a penetração da internet está relacionada com o grau de desenvolvimento de um país, a urbanização, o nível de escolarização e com competências como a proficiência em inglês. Pese embora a arduidade analítica em apartar os efeitos de diversos fatores, fica evidente que indicadores de capital cultural batem o peso de indicadores relativos ao capital económico, de variáveis compósitas como a de classe social, e relativas às coortes como a idade. Não obstante, estas variáveis devem ser articuladas para efeitos analíticos com as políticas tecnológicas e educacionais, assim como com o desenvolvimento do mercado e infraestrutura de telecomunicações, para aferir o peso de fatores societais sobre as atividades digitais dos indivíduos. 


\section{Discussão}

O padrão de disseminação generalizada de utilização da internet e a comparação europeia indiciam que o fosso digital entre diferentes grupos sociais e gerações não é uma inevitabilidade, dado que os hiatos entre grupos e escalões etários variam segundo os contextos societais, sendo mais amplos num país com as características de Portugal, com menor desenvolvimento informacional. Se, na sociedade holandesa, Loos (2012) assinala que crianças e seniores estão dispersos por um "espectro digital" e que estes grupos etários não encaixam em categorias passíveis de serem generalizadas - como as de "nativos" ou "imigrantes" digitais - é de enfatizar, no contexto português, o amontoar de desvantagens culturais e económicas por parte importante da população sénior, as quais se interligam com a falta de recursos e competências informacionais em comparação com outros setores da sociedade.

Muitas políticas digitais executadas no passado e implementadas no presente patenteiam um enfoque nos setores mais jovens e na educação, na modernização do tecido económico e da máquina administrativa do Estado. Porém, é nos seniores, nos setores pouco qualificados ou desinseridos do mercado de trabalho, e afastados dos centros urbanos, que encontramos os casos mais gritantes de infoexclusão e que constituem os grupos que mais distanciam Portugal de outros parceiros europeus. É de recordar que os atuais seniores estavam na idade madura quando há 15 anos ocorria o "choque tecnológico" e eram jovens adultos nos anos 1990, quando as políticas para a sociedade de informação começaram a ser implementadas. Os dados sugerem, portanto, à falta de uma melhor avaliação, um impacto reduzido das políticas tecnológicas nas vidas de muitos portugueses e, muito provavelmente, aquém do pretendido e das expectativas criadas. Muitos programas centraram-se nas infraestruturas e no "modelo dos dispositivos", recaindo sobre os aspetos de primeira ordem do fosso digital, isto é, relativos ao acesso, e dentro da população adulta, deixaram de fora setores especialmente vulneráveis da sociedade.

Tendo em conta outras diferenciações entre grupos e sociedades quanto à qualidade das modalidades de uso das redes digitais, outros critérios devem ser considerados, nomeadamente, os relativos à qualificação informacional da população de acordo com parâmetros de literacia digital e aos seus efeitos na condução da vida pessoal, na educação, no trabalho e na produtividade, e na modernização económica e administrativa. A este respeito, os dados do World Internet Project (WIP) para 2010 indicavam diferenças entre países, entre eles, Portugal: os hábitos digitais dos polacos tendem a ser mais pautados pelo uso de media sociais e plataformas de entretenimento, os internautas portugueses tendem a privilegiar a utilização de ferramentas de comunicação, e os respondentes de sociedades informacionalmente mais desenvolvidas como o 
Japão, Suécia, EUA e Israel tendem a privilegiar usos digitais mais amplos, utilitários e evidenciam o interesse na procura de informação (Lapa e Cardoso, 2013).

Em suma, podemos dizer que Portugal ainda está longe de alcançar as carruagens da frente do desenvolvimento informacional na Europa. Apresenta taxas de acesso e uso da internet mais baixas do que a maioria das sociedades europeias, e disparidades regionais notáveis. Demais, entre os não utilizadores portugueses é expectável que haja mais pessoas sem qualquer tipo de suporte social quanto ao uso das TIC, caso necessitem, e, portanto, totalmente excluídas no espetro da exclusão/inclusão digital. Podemos assim constatar que ainda se faz sentir na sociedade portuguesa o peso de variáveis tradicionais de desigualdade social.

Para responder à questão inicial, os dados indicam que, de facto, Portugal procura ainda o comboio Europeu do desenvolvimento informacional. Mas outra questão associada se coloca: estará o comboio perdido ou simplesmente atrasado. Para perceber melhor se a sociedade portuguesa apresenta um rumo delineado de modo ascendente, é necessária uma análise diacrónica mais detalhada que permita perceber se, apesar de tudo, Portugal tem condições para encurtar o seu atraso relativo face a outras sociedades informacionalmente mais avançadas.

Quanto a implicações para políticas públicas, existem novos desafios trazidos por novos patamares de desigualdade. Um exemplo é a utilização das redes digitais como forma de inserção económica dos consumidores no mercado de bens e serviços. Como apontam os dados do INE de 2017, 34\% da população residente entre os 16 e 74 anos referiu ter utilizado a internet para fazer encomendas de bens ou serviços. Todavia, estes consumidores online são essencialmente jovens na medida em que a utilização do comércio eletrónico é mais frequente até aos 34 anos. Estes indicadores relevam ainda a existência de uma proporção significativa de internautas que afirma recorrer à internet para adquirir produtos e serviços relativos a um nível de vida mediano numa sociedade como a portuguesa, como alojamento (42\%), bilhetes de transporte ou outros preparativos para viagens ( $41 \%$ ) e bilhetes para espetáculos ou eventos culturais ou desportivos (32\%). Não obstante o claro aumento face ao início da década (15\%, em 2010), a proporção de indivíduos que, em Portugal, efetuaram compras pela internet mantém-se expressivamente abaixo da média da UE-28 (menos 24 p. p. em 2016).

Este é um dado importante uma vez que as modalidades de comércio online podem contribuir para fazer frente a desvantagens como a insularidade, a distância face aos centros urbanos ou grandes mercados de consumo, e diminuir disparidades regionais neste âmbito. É o que tem ocorrido na Austrália, um país comparativamente afluente, mas distante dos grandes mercados de consumo da Europa e América do Norte, que revelou ter condições propícias ao florescimento do consumo online. Neste quadro, como assinala Ewing (2011), criaram-se 
condições para transpor problemas associados à distância e dispersão populacional, permitindo que os consumidores comprem diretamente aos fabricantes ou retalhistas de mercados distantes, colocando os australianos na vanguarda do comércio eletrónico. Entre os países que recolheram dados em 2008/2009 no âmbito do World Internet Project (incluindo os EUA), é mais provável que os australianos procurem informações sobre produtos semanalmente (57\%) e comprem pelo menos uma vez por mês pela internet (52\%). E, como vimos, a população portuguesa ainda está longe desses valores hoje em dia. O comércio eletrónico tem ainda o potencial de resolver problemas de assimetria nas informações disponibilizadas aos consumidores, isto é, permitir que estes, independentemente do local onde estejam, comparem rápida e facilmente produtos e preços.

Ainda neste âmbito, num recente artigo que poderia constituir uma resposta a Compaine (2001), van Duersen e van Dijk (2019) sustentam que o fosso digital de primeira ordem continua a constituir um problema na Holanda, um dos países europeus mais ricos e informacionalmente avançados, dado que as diferenças no acesso físico às TIC têm sido reconfiguradas em desigualdades naquilo que designam de acesso material, que engloba os meios necessários para manter o uso da internet ao longo do tempo, como dispositivos de computador (por exemplo, computadores de mesa ou portáteis atualizados, tablets, Smart TVs), software (assinaturas) e equipamentos periféricos (impressoras, discos rígidos adicionais, etc.). As novas fraturas materiais aparecem como resultado de mudanças tecnológicas rápidas, da grande variedade de dispositivos disponíveis ao público em geral e do facto que nem todos os dispositivos oferecem as mesmas oportunidades online. Como notam os autores (2019, p. 372), as diferenças estruturais aparecem quando segmentos específicos da população, sistematicamente e por períodos prolongados, aproveitam os melhores dispositivos e periféricos, enquanto outros usam dispositivos (como por exemplo, smartphones menos capazes ou desatualizados) que permitem menos oportunidades (no uso, por exemplo, de aplicações específicas). Mas, se assim é no seio da sociedade holandesa, não será difícil antever o que revelaria uma futura pesquisa comparada entre Portugal e a Holanda que englobasse estes indicadores mais finos relativos às desigualdades no acesso material.

\section{Conclusões}

Para que Portugal se aproxime das carruagens da frente do desenvolvimento informacional é necessário incidir sobre um conjunto de indicadores de base que informem estratégias de esbatimento das desigualdades intra-societais e face aos parceiros europeus. Além disso, ainda está por aferir até que ponto é provável ou 
mesmo eficaz que Portugal siga os mesmos caminhos de outros países da Europa para a inclusão digital dos seus cidadãos. É expectável que mais investigações como esta possam servir de suporte para identificar quem privilegiar em termos de políticas de acesso e de fomento de competências digitais e quais deverão ser as medidas desejáveis e exequíveis do Estado, e da sua intervenção no mercado, na promoção de uma Sociedade de Informação para todos, fazendo os ajustes necessários ao delineado e previsto nos documentos produzidos desde os anos 90 .

A pesquisa de van Duersen e Helsper (2018), focada mais uma vez na Holanda, lança pistas sobre a relação entre desenvolvimento informacional e desenvolvimento social lato sensu. Os autores detetaram e isolaram benefícios "colaterais" das atividades online noutros domínios de atividade, independentemente das características socioeconómicas ou socioculturais das pessoas. Tal resultado lança esperanças a uma sociedade como a portuguesa, pois indicia que o desenvolvimento informacional não tem que estar inteiramente atrelado ao desenvolvimento económico, nem está fatalmente comprometido pelo peso da distribuição desigual de capitais (em particular, cultural e económico). As políticas públicas e os programas de literacia digital podem fazer a diferença, retificando potencialmente as desigualdades digitais quanto aos resultados tangíveis das atividades online. Tal meta poderá ser atingida por meio de iniciativas de formação de competências direcionadas e de provisionamento de oportunidades, para que indivíduos de diferentes setores da sociedade possam envolver-se no mundo digital de várias formas, o que, por sua vez, poderá trazer benefícios na qualidade da atividade social noutros domínios (no mercado de trabalho, no consumo, no acesso à cultura e ao conhecimento, no que respeita o capital social e o bem-estar subjetivo, para dar alguns exemplos). Deste modo, van Duersen e Helsper defendem que uma abordagem semiológica poderá ser mais eficaz do que uma abordagem económica para pensar e combater as desigualdades digitais. Só o aprofundamento da análise em pesquisas futuras poderá permitir perceber, com maior acuidade, estas dinâmicas e se as modalidades de domesticação da internet diluem-se instrumentalmente noutras desigualdades ou se os diversos níveis da desigualdade digital poderão vir a ser elevados aos principais eixos de fratura das sociedades da informação e do conhecimento.

\section{Notas}

Por decisão pessoal, os autores do texto escrevem segundo o novo acordo ortográfico.

1 O estudo da ERC foi publicado em 2016, mas os dados que o suportam foram recolhidos em 2015. 


\section{Agradecimentos}

Os autores agradecem os preciosos comentários e sugestões dos revisores que permitiram melhorar a qualidade geral do presente artigo.

\section{Referências}

Blank, G., e Dutton, W. (2012). The emergence of next generation internet users. Em J. Hartley, J. Burgess, e A. Bruns (Orgs.), Blackwell companion to new media dynamics (pp. 122-141). Londres: Wiley-Blackwell.

Cardoso, G., Espanha, R., e Araújo, V. (Org.) (2009). Da comunicação de massa à comunicação em rede. Porto: Porto Editora.

Cardoso, G., Liang, G. e Lapa, T. (2013). Cross-national comparative perspectives from the world internet project. Em W. Dutton (Org.), The Oxford handbook of internet studies (pp. 216-236). Oxford: Oxford University Press.

Castells, M. (2000). Toward a sociology of the network society. Contemporary Sociology, 29(5), 693-699.

CIES-IUL. (2003-2013). Inquérito sociedade em rede. Lisboa: Centro de Investigação e Estudos de Sociologia.

Compaine, B. (2001). Information gaps. Em B. Compaine (Org.), The digital divide: Facing a crisis or creating a myth? (pp. 105-118). Cambridge, MA: MIT Press.

DiMaggio, P., Hargittai, E., Celeste, C., e Shafer, S. (2004). Digital inequality: From unequal access to differentiated use. Em K. Neckerman (Org.), Social inequality (pp. 355-400). Nova Iorque: Russell Sage.

Emmanouilides, C., e Hammond, K. (2000). Internet usage: Predictors of active users and frequency of use. Journal of Interactive Marketing, 14(2), 17-32.

ERC. (2016). As novas dinâmicas do consumo audiovisual em Portugal. Lisboa: ERC.

Eurostat. (2017). Digital economy and society statistics - Households and individuals. Luxemburgo: Eurostat.

Ewing, S. (2011). Consuming online in Australia. Em P. Newton (Org.), Urban consumption (pp. 105-122). Csiro Publishing.

Haddon, L. (2007). Roger Silverstone's legacies: Domestication. New Media and Society, 9, 16-24.

Hargittai, E., e Hinnart, A. (2008). Digital inequality: Differences in young adults use of the internet. Communication Research, 35(5), 602-621.

Hargittai, E., e Hsieh, Y. (2013). Digital inequality. Em W. Dutton (Org.), The Oxford handbook of internet studies (pp. 129-150). Oxford: Oxford University Press.

Helsper, E. J. (2010). Gendered internet use across generations and life stages. Communication Research, 37(3), 352-374.

Hynes, D., e Rommes, E. (2005). 'Fitting the internet into our lives': IT courses for disadvantaged users. Em T. Berker, M. Hartmann, Y. Punie, e K. Ward (Eds.), 
Domestication of media and technologies (pp. 123-44). Maidenhead: Open University Press.

INE. (2007). Inquérito à utilização de tecnologias da informação e da comunicação pelas famílias. Lisboa: Instituto Nacional de Estatística.

Jenkins, H., Purushotma, R., Weigel, M., Clinton, K., e Robison, A. J. (2009). Confronting the challenges of participatory culture: Media education for the 21st century (MacArthur The John D. and Catherine T. MacArthur Foundation Reports on Digital Media and Learning). Cambridge, MA: MIT Press.

Lapa, T. (2014). A infância em rede: Media e quadros de existência infantis na sociedade em rede (Tese de doutoramento). ISCTE-IUL, Lisboa.

Lapa, T., e Cardoso, G. (2013). What 'digital divide' between generations? A cross-national analysis using data from the world internet project. Em International Conference on Universal Access in Human-Computer Interaction (pp. 113-122). Springer, Berlin, Heidelberg.

Lapa, T., Vieira, J., Azevedo, J., e Cardoso, G. (2018). As desigualdades digitais e a sociedade portuguesa: Divisão, continuidades e mudanças. Em R. Carmo, J. Sebastião, J. Azevedo, S. da C. Martins, e A. F. da Costa (Orgs.), Desigualdades sociais: Portugal e a Europa (pp. 257-270). Lisboa: Mundos Sociais.

Livingstone, S. (2004). What is media literacy?. Intermedia, 32(3), 18-20.

Livingstone, S., e Haddon L. (Orgs.) (2009). EU kids online: Final report. Londres: LSE, EU Kids Online.

Loos, E. (2012). Senior citizens: Digital immigrants in their own country?. Observatorio, 6(1), $1-23$.

Mauritti, R. (2011). Viver só: Mudança social e estilos de vida. Lisboa: Mundos Sociais.

Pereira, S., e Melro, A. (2014). Acesso e usos do computador Magalhães na escola e em casa: Um estudo no concelho de Braga. Em S. G. da Silva, e S. Pereira (Coord.), Atas do 2. ${ }^{\circ}$ Congresso Literacia, Media e Cidadania. Lisboa: Gabinete para os Meios de Comunicação Social.

Reisdorf, B. (2011). Non-adoption of the internet in Great Britain and Sweden a cross-national comparison. Information, Communication \& Society, 14(3), 400-420.

Schiller, H. (1996). Information inequality: The deepening social crisis in America. Londres: Routledge.

Skryabin, M., Zhang, J., Liu, L., e Zhang, D. (2015). How the ICT development level and usage influence student achievement in reading, mathematics, and science. Computers E Education, 85, 49-58.

Smith, A. (2011). Smartphone adoption and usage. Washington: Pew Research Center, Pew Internet \& American Life Project.

Szeles, M. R. (2018). New insights from a multilevel approach to the regional digital divide in the European Union. Telecommunications Policy, 42(6), 452-463.

van Deursen, A., e Helsper, E. (2015). The third-level digital divide: Who benefits most from being online?. Em L. Robinson, S. R. Cotton, J. Schulz, e T. Hale (Eds.), Communication and information technologies annual: Digital distinctions and 
inequalities, studies in media and communications (Book 10) (pp. 29-52). Emerald Group Publishing Limited.

van Deursen, A. J. A. M., e Helsper, E. J. (2018). Collateral benefits of Internet use: Explaining the diverse outcomes of engaging with the Internet. New Media and Society, 20(7), 2333-2351.

van Deursen, A. J. A. M., e van Dijk, J. A. G. M. (2019). The first-level digital divide shifts from inequalities in physical access to inequalities in material access. New Media and Society, 21(2), 354-375.

van Dijk, J. (2005). The deepening divide: Inequality in the information society. Thousand Oaks: Sage.

Vieira, J. (2015). Consumos em rede não autorizados: Pirataria digital em Portugal (Tese de doutoramento). ISCTE-IUL, Lisboa.

Data de submissão: 17/06/2019 | Data de aceitação: 22/07/2019 